\title{
Comportamento de vigas de concreto armadas com barras de GFRP
}

Este trabalho trata sobre o comportamento estrutural de vigas de concreto armadas com barras de compósito de resina e fibras de vidro (GFRP). A partir de um programa experimental, 6 (seis) vigas de concreto armado de $150 \mathrm{~mm} \times 150 \mathrm{~mm} \times 1500 \mathrm{~mm}$ de dimensões foram ensaiadas à flexão em quatro pontos. Os parâmetros variados nestas vigas foram o material das barras (aço ou GFRP) e a taxa de armadura longitudinal ( $0,88 \%$ e $2,02 \%)$. A resistência média do concreto à compressão foi $25 \mathrm{MPa}$. Foram monitorados até a ruptura das vigas os valores de flecha, deformação específica das armaduras (transversal e longitudinal) e do concreto, e abertura de fissura no vão de flexão pura. Os resultados mostraram que as vigas com barras de GFRP apresentaram resistência próxima à das vigas com barras de aço. Por causa da menor rigidez à flexão, os valores de flecha e de abertura de fissura das vigas com barras de GFRP foram maiores que os das vigas com barras de aço.

Palavras-chave: Vigas; Concreto; Material compósito; Barras de GFRP; Flexão.

\section{Behavior of concrete beams reinforced with GFRP bars}

This work focuses on structural behavior of concrete beams reinforced with glass fiber reinforced polymer (GFRP) bars. From an experimental program, 6 (six) reinforced concrete beams of $150 \mathrm{~mm} \times 150 \mathrm{~mm} \times 1500 \mathrm{~mm}$ in dimensions were subjected to four-point flexural test. The varied parameters in these beams were the material of the bars (steel or GFRP) and the longitudinal reinforcement ratio $(0.88 \%$ and $2.02 \%)$. The average value of concrete compressive strength was 25 $\mathrm{MPa}$. The values of deflection, strain of reinforcement (transverse and longitudinal) and concrete, and crack width in the pure flexion span were monitored until the beams rupture. The results showed that the GFRP beams showed resistance close to that of the steel bars beams. Because of the lower flexural stiffness, the values of deflection and crack width of GFRP beams were higher than those of steel bars beams.

Keywords: Beams; Concrete; Composite material; GFRP bars; Bending.

Topic: Construções e Arquitetura Sustentáveis

Reviewed anonymously in the process of blind peer.
Received: 04/03/2021

Approved: 23/03/2021
Luiz Antonio Vieira Carneiro (iD

Universidade Federal Fluminense, Brasil http://lattes.cnpq.br/2431901858566512 http://orcid.org/0000-0001-7036-2048

luizcarneiro@id.uff.br

Rhoan Carlos Busquim e Silva (iD

Instituto Militar de Engenharia, Brasil

http://lattes.cnpq.br/6071942423077231

http://orcid.org/0000-0002-4962-9198

eng.rhoan@gmail.com

Ana Maria Abreu Jorge Teixeira

Instituto Militar de Engenharia, Brasil

http://lattes.cnpq.br/1454254574734029

http://orcid.org/0000-0003-3762-7192

anam@ime.eb.br
Referencing this:

CARNEIRO, L. A. V.; SILVA, R. C. B.; TEIXEIRA, A. M. A. J..

Comportamento de vigas de concreto armadas com barras de GFRP. Revista Ibero Americana de Ciências Ambientais, v.12, n.3, p.207223, 2021. DOI: http://doi.org/10.6008/CBPC21796858.2021 .003 .0019 


\section{INTRODUÇÃO}

Os materiais compósitos de resina e fibras (FRP) começaram a ser pesquisados a partir da segunda metade do século XX (DIMMOCK et al., 1969; PEARCE, 1970), nos quais se constataram a anisotropia de compósitos unidirecionais, a rigidez das fibras de carbono e a dispersão nos resultados experimentais. Devido à sua alta resistência à tração, elevada absorção ao impacto, baixo peso e não serem suscetíveis à corrosão e ao magnetismo, estes materiais têm sido aplicados em construções.

Uma das possíveis aplicações dos materiais compósitos de resina e fibras é na forma de barras de FRP em substituição às barras em aço. Estas barras de FRP podem ser fabricadas pelo processo da pultrusão, que consiste em puxar as fibras (vidro, aramida ou carbono) impregnadas com resina (poliéster, vinil-éster, éster-vinílica ou epóxi) por meio de um molde pré-aquecido e conferir a geometria desejada após a polimerização (endurecimento ou cura) do conjunto fibras-resina, de acordo com Levy Neto et al. (2006).

Segundo Jay (2019), foram utilizadas barras de compósito de resina e fibras de vidro (GFRP) na recuperação de lajes de concreto na ponte sobre o Rio Chagrin, na cidade de Cleveland, estado de Ohio nos EUA. Sua estrutura foi originalmente construída em concreto com barras de aço e, posteriormente, durante a recuperação, as barras de aço foram substituídas por barras de GFRP.

Outra aplicação de barras de GFRP na área de infraestrutura de transportes é em pavimentos rígidos. Chen et al. (2008) relataram a construção de uma pista experimental em concreto (305 m de comprimento e $25 \mathrm{~cm}$ de espessura) com armadura contínua de GFRP na cidade de Martinsburg, estado da Virgínia Ocidental nos EUA, para estudar o seu desempenho estrutural e avaliar sua diminuição de custos de manutenção.

A fim de permitir que a tuneladora, isto é, máquina utilizada na escavação de túneis com seção transversal circular, perfurasse as paredes diafragma da estação de Jardim de Alah do metrô da cidade do Rio de Janeiro, foram utilizadas, ao invés de barras de aço, barras de GFRP como armaduras destas paredes de concreto, conforme relatado por Silveira et al. (2017).

Ortigão (1996) destacou em seu trabalho o uso de barras de FRP para assegurar a durabilidade de obras de contenção de taludes naturais e de corte por meio da técnica de solo grampeado, que consiste principalmente em executar perfurações no solo para instalação destas barras e revestir o talude de solo grampeado com concreto projetado para sua proteção superficial.

Por não serem suscetíveis à corrosão, os materiais de FRP podem ser empregados em estruturas de concreto próximas a regiões marítimas, prologando sua vida útil e reduzindo a necessidade de sua manutenção, o que diminui transtornos aos usuários devidos às interdições e aos elevados gastos financeiros.

O uso de materiais de FRP está se tornando cada vez mais presente no mundo. A comunidade europeia e alguns países, tais como EUA e Canadá, já possuem códigos específicos para projeto e construção de estruturas de concreto armadas com barras de FRP e as pesquisas sobre o tema estão mais avançadas do que no Brasil.

O desenvolvimento desta pesquisa na área permite o acúmulo de conhecimento sobre o assunto e 
pode ajudar na elaboração de norma brasileira específica, pois este trabalho experimental se deu sob as condições climáticas e utilizaram materiais nacionais, o que o torna relevante.

O objetivo deste trabalho é apresentar o comportamento de vigas de concreto armadas com barras em GFRP até sua ruptura, em termos dos valores de flecha, deformação específica das armaduras (transversal e longitudinal) e do concreto, e abertura de fissura no vão de flexão pura. Estes valores foram comparados os obtidos de vigas de referência, ou seja, vigas de concreto armado, que são formadas por concreto simples e barras de aço.

\section{REVISÃO TEÓRICA}

Pendhari et al. (2008) apresentaram o estado da arte sobre a aplicação de FRP no reforço externo de elementos estruturais de concreto, enquanto Hollaway (2010) listou diferentes aplicações de barras de FRP como armadura interna de elementos estruturais de concreto.

Kara et al. (2012) propuseram um método numérico iterativo para prever o comportamento à flexão e calcular a flecha no meio do vão de vigas de concreto armadas com barras de FRP, com base na sua relação momento-curvatura e levando-se em conta o equilíbrio de forças e a compatibilidade entre tensões. Concluíram que as flechas e curvaturas teóricas de vigas de concreto armadas com barras de GFRP e de compósito de resina e fibras de carbono (CFRP) foram próximas das flechas e curvaturas experimentais disponíveis na literatura. Além disto, os valores de momento resistente teórico de 107 vigas de concreto armadas com barras de GFRP e de CFRP foram similares aos respectivos valores experimentais.

Esses autores também verificaram que o guia ACl 440.1R-06 (2006) sugere formulações que acarretam flechas teóricas próximas das experimentais para vigas simplesmente apoiadas de concreto armadas com barras de FRP e que subestimam as flechas de vigas contínuas de concreto armadas com barras de FRP. A fim de contornar este problema, os autores inseriram nas formulações um fator de correção para a rigidez à flexão, o que conduziu flecha teórica mais próxima da experimental nas vigas contínuas de concreto armadas com barras de FRP.

Após realizado um estudo paramétrico, Kara et al. (2012) constataram que a resistência do concreto à compressão não tem efeito no momento resistente de vigas de concreto subarmadas com barras de FRP, mas influencia significativamente o de vigas de concreto superarmadas com barras de FRP. Por outro lado, um grande aumento na taxa das barras de FRP aumenta ligeiramente o momento resistente das vigas de concreto superarmadas com barras de FRP, mas reduz bastante sua flecha após a formação da primeira fissura.

Saleh et al. (2019) ensaiaram oito vigas de concreto armadas com barras de GFRP de seção retangular e de $100 \mathrm{~mm} \times 150 \mathrm{~mm} \times 2400 \mathrm{~mm}$ de dimensões, nas quais se variaram a taxa da armadura longitudinal $(0,5 \%, 1,0 \%$ e 2,0\%) e a resistência do concreto à compressão (47 MPa ou $66 \mathrm{MPa})$. Observou-se que as vigas dimensionadas como superarmadas, conforme o guia ACl 440.1R-15 (2015) e a norma CAN/CSA-S806-12 (2012), romperam por esmagamento do concreto, enquanto as vigas dimensionadas como subarmadas romperam pela ruptura das barras de GFRP. As vigas dimensionadas como balanceadas romperam por ambos 
os modos de ruptura.

Esses autores concluíram que o comportamento das vigas de concreto armadas com barras de GFRP depende da taxa de armadura e da resistência do concreto à compressão. $O$ aumento da taxa de armadura de GFRP nas vigas incrementou sua carga de ruptura, independentemente da resistência do concreto à compressão. Quando a taxa de armadura de GFRP foi aumentada de $1 \%$ para $2 \%$, houve um acréscimo médio de $22 \%$ na carga de ruptura da viga. No entanto, a carga ruptura aumentou em uma média de $180 \%$ quando a taxa de armadura de GFRP passou de $0,5 \%$ para $1,0 \%$, pois o modo de ruptura mudou de ruptura da armadura de GFRP para esmagamento do concreto.

Ainda segundo Saleh et al. (2019), as recomendações de projeto sobre vigas de concreto armadas com barras de GFRP inseridas no guia ACl 440.1R-15 (2015) e na norma CAN/CSA-S806-12 (2012) conduziram a valores conservadores em termos de carga de ruptura e flechas no meio do vão na ruptura das vigas superarmadas, embora superestimaram estes valores para as vigas subarmadas e balanceadas.

Abdelkarim et al. (2019) realizaram ensaio à flexão de oito vigas de concreto armadas com barras de GRFP de seção retangular e de $200 \mathrm{~mm}$ × 300 mm x 3100 mm de dimensões, tendo sido variados a resistência do concreto à compressão (35 MPa ou $65 \mathrm{MPa}$ ) e o diâmetro das barras de GFRP (12 mm, $16 \mathrm{~mm}, 20 \mathrm{~mm}$ e $25 \mathrm{~mm}$ ), o que levou a taxas de armadura de GFRP variando de $0,38 \%$ a 1,63\%. Verificou-se que as formulações do guia ACI 440.1R-15 (2015) e da norma CAN/CSA-S806-12 (2012) levaram a valores de momento resistente teórico muito próximos do momento resistente experimental das vigas. Com o aumento da taxa de armadura da GFRP nas vigas, sua rigidez à flexão aumentou significativamente e sua abertura da fissura de flexão diminuiu. As vigas com concreto de alta resistência (65 MPa) apresentaram índice de ductilidade maior que o das vigas com concreto de resistência normal (35 MPa).

Os modelos de cálculo para o dimensionamento à flexão de vigas de concreto armadas com barras de FRP adotam a teoria da flexão simples, cujas hipóteses são: manutenção da seção transversal plana até a ruptura da viga; perfeita aderência entre a barra de FRP e o concreto; comportamento da barra de FRP elástico linear; resistência do concreto à tração e resistência da barra de FRP à compressão nulas; e deformação última do concreto entre os limites de 3\%o e 3,5\%, dependendo do modelo de cálculo utilizado.

O modo de ruptura mais adequado para as vigas de concreto armadas com barras de FRP é aquele em que ocorre o esmagamento do concreto, sem que haja a ruptura das barras de FRP, pois o comportamento das barras de FRP é elástico linear e frágil até a ruptura, ao contrário do comportamento dúctil das barras de aço.

A resistência de vigas de concreto armadas com barras de FRP é controlada pela ocorrência do esmagamento do concreto ou da ruptura das barras de FRP, segundo o guia ACI 440.1R-15 (2015). Neste guia recomenda-se comparar a taxa de armadura de FRP $\rho_{f}$ (relação entre a área total da armadura longitudinal de FRP $A_{f}$ e o produto entre a largura $b$ e a altura útil $d$ da seção transversal da viga) à taxa balanceada de armadura de FRP $\rho_{f b}$, cujo valor determina o esmagamento do concreto e a ruptura das barras de FRP de forma simultânea e é dado pela Equação 1. 


$$
\rho_{f b}=0,85 \beta_{1} \frac{f_{c}}{f_{f}} \frac{E_{f} \varepsilon_{c u}}{E_{f} \varepsilon_{c u}+f_{f}}
$$

onde $\beta_{1}$ é a razão entre a altura do bloco simplificado de tensões de compressão no concreto e a altura da linha neutra, igual a 0,85 para concretos com $f_{c}$ até $28 \mathrm{MPa}$ e reduzido em 0,05 para cada aumento em $f_{c}$ de $7 \mathrm{MPa} ; f_{f}$ é a resistência à tração da armadura interna de FRP; $E_{f}$ é o módulo de elasticidade longitudinal da armadura interna de FRP; e $\varepsilon_{c u}$ é a deformação última do concreto.

De acordo com o guia ACl 440.1R-15 (2015), o valor do momento fletor resistente de uma seção de viga de concreto armada com barras de FRP é dado pela Equação 2, quando o valor de $\rho_{f}$ é maior que o valor de $\rho_{f b}$ (v. Equação 2), caso contrário utiliza-se a Equação 3.

$$
M_{u}=\rho_{f} \sigma_{f}\left(1-0,59 \frac{\rho_{f} \sigma_{f}}{f_{c}}\right) b d^{2}
$$

onde $\sigma_{f}$ é a tensão de tração na armadura de FRP (v. Equação 4) e $f_{c}$ é a resistência do concreto à compressão.

$$
M_{u}=A_{f} f_{f}\left(d-\frac{\beta_{1} x_{b}}{2}\right)
$$

onde $x_{b}$ é a altura da linha neutra balanceada da viga (considerando as deformações últimas do concreto e da barra de FRP iguais a $3 \%$ e $\left.\varepsilon_{f u}\right)$.

$$
\sigma_{f}=\left(\sqrt{\frac{\left(E_{f} \varepsilon_{c u}\right)^{2}}{4}+\frac{0,85 \beta_{1} f_{c}}{\rho_{f}} E_{f} \varepsilon_{c u}}-\frac{E_{f} \varepsilon_{c u}}{2}\right) \leq f_{f}
$$

A norma brasileira ABNT NBR 6118 (2014) trata sobre o projeto de vigas em concreto somente com barras de aço. A teoria da flexão simples é utilizada no dimensionamento de vigas em concreto armado e adota manutenção da seção transversal plana até a ruptura da viga, perfeita aderência entre a barra de aço e o concreto, resistência do concreto à tração nula, e deformações últimas do concreto e do aço iguais a $3,5 \%$ e $10 \%$.

Sugere-se neste trabalho que o momento fletor resistente de vigas em concreto armadas com barras de GFRP (v. Equação 5) possa ser obtido por meio do uso da teoria da flexão simples, segundo a norma ABNT NBR 6118 (2014), limitando-se a deformação última das barras de GFRP.

$$
M_{u}=\alpha_{c} f_{c} \lambda x_{u} b\left(d-\frac{\lambda x_{u}}{2}\right)
$$

onde $\alpha_{c}$ é o parâmetro de redução da resistência do concreto na compressão, igual a 0,85 , para concretos com $f_{c}$ até $50 \mathrm{MPa}$, ou 0,85[1,0-( $\left.\left.f_{c}-50\right) / 200\right]$, para concretos com $f_{c}$ maior que $50 \mathrm{MPa} ; \lambda$ é relação entre a altura do diagrama retangular de compressão equivalente e a altura da linha neutra na ruptura $x_{u}$ igual a 0,80, para concretos com $f_{c}$ maior que $50 \mathrm{MPa}$, ou $0,80-\left(f_{c}-50\right) / 400$.

A altura da linha neutra na ruptura $x_{u}$ da Equação 5 deve ser menor que $45 \%$ da altura útil da viga $d$ e igual à Equação 6.

$$
x_{u}=\frac{E_{f} \varepsilon_{f u} A_{f}}{\alpha_{c} f_{c} \lambda b}
$$

onde $\varepsilon_{f u}$ é a deformação da armadura interna de FRP na ruptura da viga, dada em \%o pela Equação 7 e obtida a partir de resultados experimentais deste trabalho e de resultados encontrados na literatura 
(BENMOKRANE et al., 1996; TAVARES, 2006; CHITSAZAN et al., 2010; ABDELKARIM et al., 2019) conforme a Figura 1.

$$
\varepsilon_{f u}=-4,6\left(\rho_{f} \frac{f_{f}}{f_{c}} \frac{E_{f}}{E_{c S}}\right)+15,5
$$

onde $E_{C S}$ é o módulo de elasticidade secante do concreto, dado pela Equação 8, válida para $f_{C}$ entre $20 \mathrm{MPa}$ e $50 \mathrm{MPa}$, ou pela Equação 9, válida para $f_{c}$ acima de $50 \mathrm{MPa}$ até $90 \mathrm{MPa}$, conforme item 8.2.8 da ABNT NBR 6118 (2014) quando não forem realizados ensaios.

$$
\begin{array}{ll}
E_{C S}=\alpha_{i} \alpha_{E} 5600 \sqrt{f_{c}} & \text { (Equação 8) } \\
E_{C S}=\alpha_{i} \alpha_{E} 21500\left(f_{c} /{ }_{10}+1,25\right)^{1 / 3} & \text { (Equação 9) }
\end{array}
$$

sendo $\alpha_{i}$ um coeficiente menor ou igual à unidade e dado pela Equação 10 e $\alpha_{E}$ igual a 1,2, para agregado graúdo do tipo basalto ou diabásio, ou 1,0, para agregado graúdo do tipo granito ou gnaisse, ou 0,9, para agregado graúdo do tipo calcário, ou 0,7, para agregado graúdo do tipo arenito.

$$
\alpha_{i}=0,80+0,20 f_{c} / 80
$$

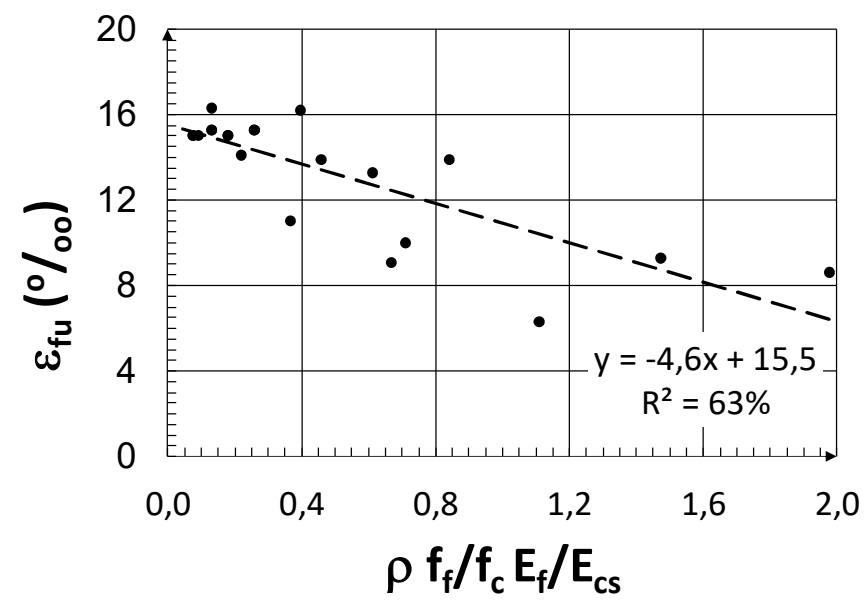

Figura 1: Valores de deformação da armadura de FRP em função de (ㅁ] $f_{f} / f_{c} E_{f} / E_{c s}$ ) encontrados na literatura.

Segundo o guia ACl 440.1R-15 (2015), o momento de fissuração de uma seção de viga de concreto armada com barras de FRP é dado pela Equação 11, enquanto a norma ABNT NBR 6118 (2014) sugere a Equação 12, para concretos com $f_{c}$ até $50 \mathrm{MPa}$, ou a Equação 13, para concretos com $f_{c}$ maior que $50 \mathrm{MPa}$, para o momento de fissuração de uma seção retangular de viga de concreto armado com barras em aço.

$$
M_{r}=\frac{0,62 \sqrt{f_{c}} I_{C}}{y_{t}}
$$

onde $I_{c}$ é o momento de inércia da seção bruta de concreto e $y_{t}$ é a distância do centro de gravidade da seção à fibras mais tracionada.

$$
\begin{aligned}
& M_{r}=\frac{0,315 f_{c}^{2 / 3} I_{c}}{y_{t}} \\
& M_{r}=\frac{3,18 \ln \left(1+0,11 f_{c}\right) I_{c}}{y_{t}}
\end{aligned}
$$

\section{MATERIAIS E MÉTODOS}

Foram ensaiadas à flexão seis vigas de concreto de $150 \mathrm{~mm}$ x $150 \mathrm{~mm}$ x $1500 \mathrm{~mm}$ de dimensões, 
sendo duas em concreto armado, outras duas armadas com barras longitudinais de GFRP e estribos de aço e as restantes armadas com barras longitudinais e estribos de GFRP. O parâmetro variado nos ensaios foi a taxa de armadura longitudinal das vigas (0,88\% e 2,02\%), que neste trabalho é definida como a relação entre a área total da armadura longitudinal e o produto entre a largura e a altura útil da seção transversal da viga.

Todas as vigas foram biapoiadas sobre apoios de 1ㅇ e 2을 gêneros, com vão livre de $1350 \mathrm{~mm}$, e simetricamente carregadas com duas cargas concentradas distantes dos apoios, conforme pode-se notar na Figura 2. Os ensaios foram realizados no Laboratório de Materiais de Construção e Concreto do Instituto Militar de Engenharia.

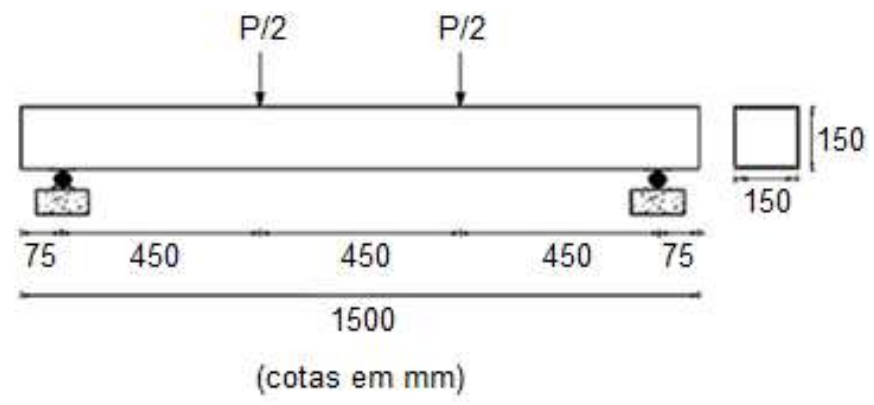

Figura 2: Ensaio realizado no programa experimental.

O concreto utilizado nas vigas era convencional, com resistência média à compressão de cerca de $25 \mathrm{MPa}$, cujo traço em peso foi 1: 2,41: 3,26: 0,59: 0,004 (cimento CPII-E-32: areia: 50\% brita $0+50 \%$ brita 1: relação água-cimento), tendo consumo de $316 \mathrm{~kg}$ de cimento por $\mathrm{m}^{3}$ de concreto. $\mathrm{O}$ abatimento do tronco de cone do concreto foi $(50 \pm 10) \mathrm{mm}$, de acordo com a norma ABNT NBR NM 67 (1998).

$\mathrm{O}$ aço das armaduras longitudinal e transversal era do tipo CA-50. $\mathrm{Na}$ armadura longitudinal, foram utilizadas barras de $10 \mathrm{~mm}$ de diâmetro, cujos valores de resistência média ao escoamento e de módulo de elasticidade foram 650 MPa e 208 GPa. Barras de 6,3 mm de diâmetro, espaçadas de $50 \mathrm{~mm}$ ao longo do comprimento da viga, foram utilizadas na armadura transversal de $584 \mathrm{MPa}$ de resistência média ao escoamento e de 208 GPa de módulo de elasticidade.

As barras longitudinais de GFRP, de $10 \mathrm{~mm}$ de diâmetro, da armadura de tração das vigas com estribos de aço tinham resistência à tração e módulo de elasticidade iguais a $743 \mathrm{MPa}$ e $55 \mathrm{GPa}$. Sua composição continha em média $56 \%$ de fibras de vidro tipo E e $29 \%$ resina isoftálica de fração em volume.

Para as vigas de concreto armadas com barras longitudinais de GFRP e estribos de GFRP, as barras longitudinais de $10 \mathrm{~mm}$ de diâmetro tinham resistência à tração e módulo de elasticidade iguais a $793 \mathrm{MPa}$ e $57 \mathrm{GPa}$, cuja composição continha em média 63\% de fibras de vidro tipo E e $28 \%$ resina epóxi éster vinílica de fração em volume. Os estribos de 6,3 $\mathrm{mm}$ de diâmetro, espaçados de $50 \mathrm{~mm}$ ao longo do comprimento da viga, possuíam $857 \mathrm{MPa}$ de resistência média à tração e 59 GPa de módulo de elasticidade.

As Figuras 3 e 4 ilustram o detalhamento das armaduras longitudinal e transversal das vigas com taxas de armadura longitudinal de $0,88 \%$ e de $2,02 \%$.

Devido às barras longitudinais de GFRP de $10 \mathrm{~mm}$ de diâmetro serem retas sem ganchos, foram inseridos ganchos de aço ou de GFRP de $10 \mathrm{~mm}$ nas extremidades das barras retas de GFRP a fim de melhorar 
sua ancoragem no concreto, segundo se vê nas Figuras 5 e 6 .

O dimensionamento das vigas em concreto armado foi realizado utilizando-se a norma ABNT NBR 6118 (2014), de forma que o modo de ruptura somente ocorresse por flexão, isto é, com esmagamento do concreto e escoamento da armadura.

Com o objetivo de se obter a deformação das armaduras, cada uma das barras longitudinais da primeira camada das vigas foi instrumentada no seu meio de vão com dois extensômetros elétricos de resistência. Em uma das pernas do estribo localizado no meio do vão de cisalhamento (distância entre a carga concentrada e o apoio), também foram colados dois extensômetros elétricos de resistência. A deformação do concreto à compressão foi avaliada por meio de extensômetro elétrico de resistência colado em uma das faces laterais no meio do vão a partir de $10 \mathrm{~mm}$ do bordo superior das vigas.

A medição das flechas no meio do vão das vigas e das fissuras de flexão foi realizada com o uso de um transdutor de deslocamento e de um medidor óptico com lupa graduada de 0,02 mm de precisão.

\section{RESULTADOS}

A Tabela 1 apresenta os valores médios de resistência à compressão $\left(f_{c}\right)$, resistência à tração por compressão diametral $\left(\mathrm{f}_{c, s p}\right)$ e módulo de elasticidade secante $\left(\mathrm{E}_{c s}\right)$ do concreto empregado nas vigas ensaiadas. Estes valores médios foram obtidos por meio da média entre os resultados de 3 (três) corpos de prova cilíndricos de concreto de $100 \mathrm{~mm}$ x 200 mm de dimensões e com o uso das normas ABNT NBR 5739 (2018), ABNT NBR 7222 (2011) e ABNT NBR 8522 (2017), respectivamente.

Além disso, na Tabela 1 são apresentados os valores teóricos de resistência à tração por compressão diametral $\left(f_{c, s p ~ t e o}\right)$ e módulo de elasticidade secante $\left(E_{c s, t e o}\right)$ do concreto, que foram encontrados por meio da formulação dos itens 8.2.5 e 8.2.8 da norma ABNT NBR 6118 (2014) considerando-se a resistência característica do concreto à compressão $\left(f_{c k}\right)$ da formulação igual ao valor de $f_{c}$ experimental.

A nomenclatura das vigas, listadas na Tabela 1 e 2, foi adotada da seguinte forma: ' $V n$ ' representa a viga número $n$; a primeira letra ' $A$ ' (aço) ou ' $V$ ' (GFRP), o tipo de material usado na armadura longitudinal; a segunda letra ' $A$ ' (aço) ou ' $V$ ' (GFRP), o tipo de material usado na armadura transversal; e o número '0,88' ou '2,02', o valor da taxa de armadura longitudinal em percentagem.

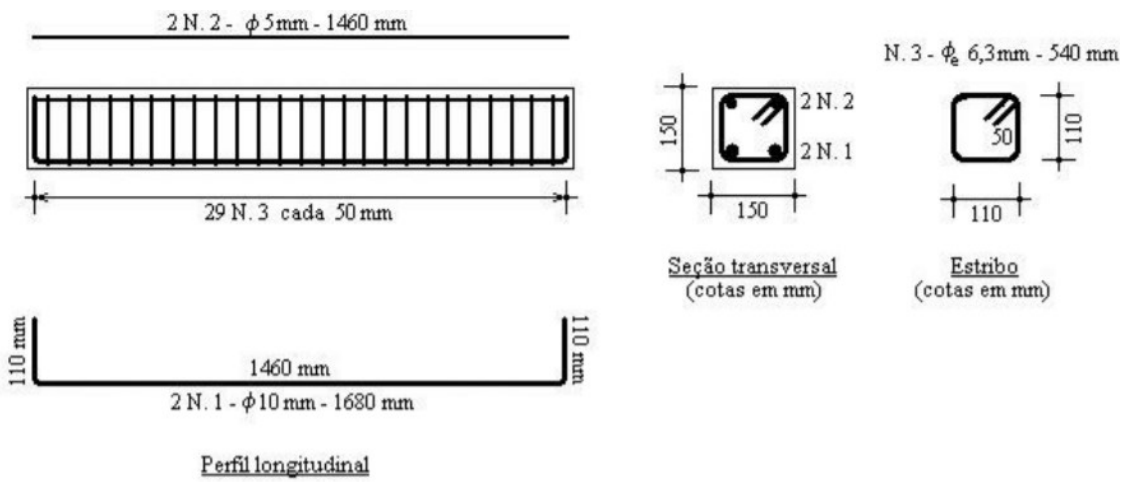

(a) armaduras longitudinal e transversal de aço 


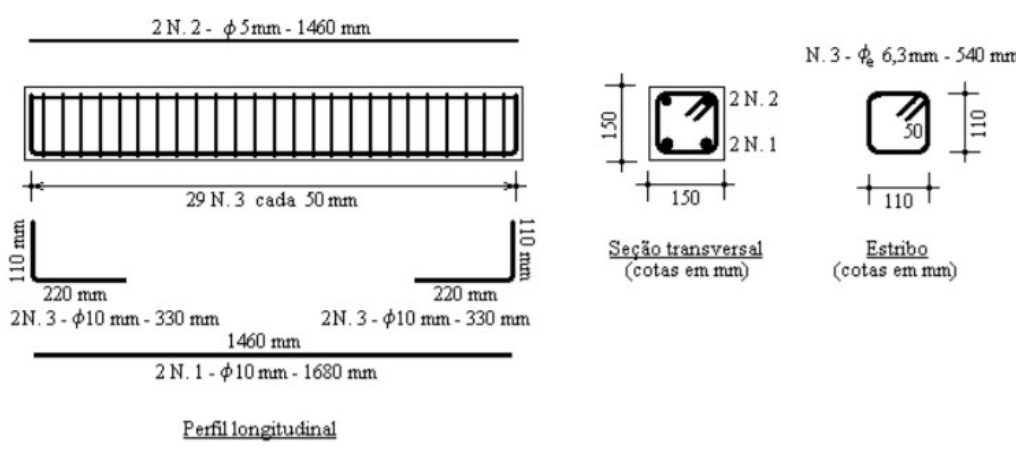

(b) armaduras longitudinal de GFRP e transversal de aço ou de GFRP

Figura 3: Detalhamento das armaduras das vigas com taxa longitudinal de $0,88 \%$.
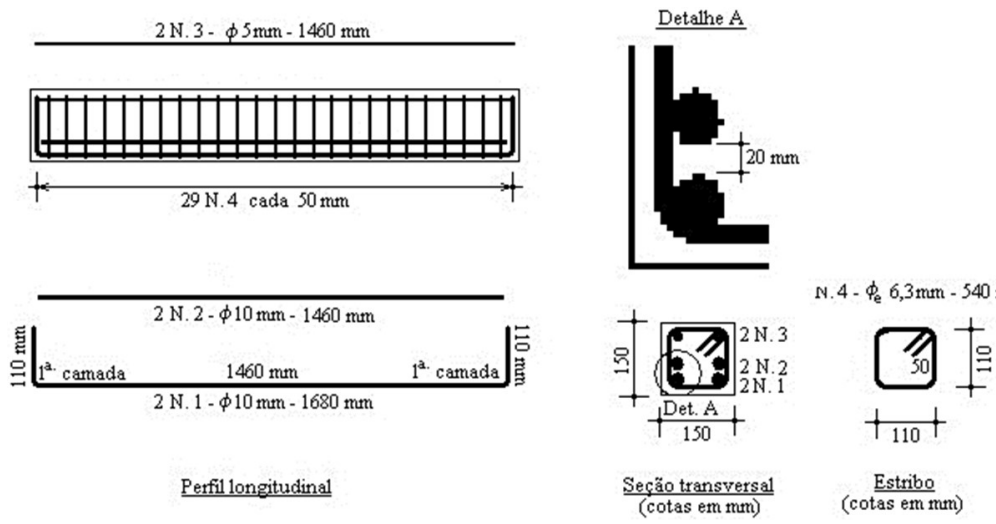

(a) armaduras longitudinal e transversal de aço
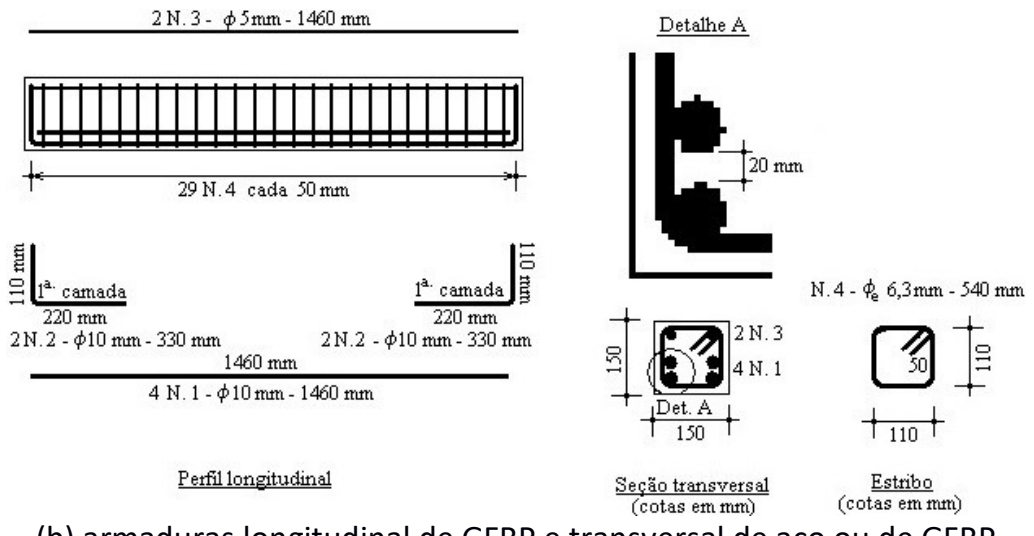

(b) armaduras longitudinal de GFRP e transversal de aço ou de GFRP

Figura 4: Detalhamento das armaduras das vigas com taxa longitudinal de $2,02 \%$.
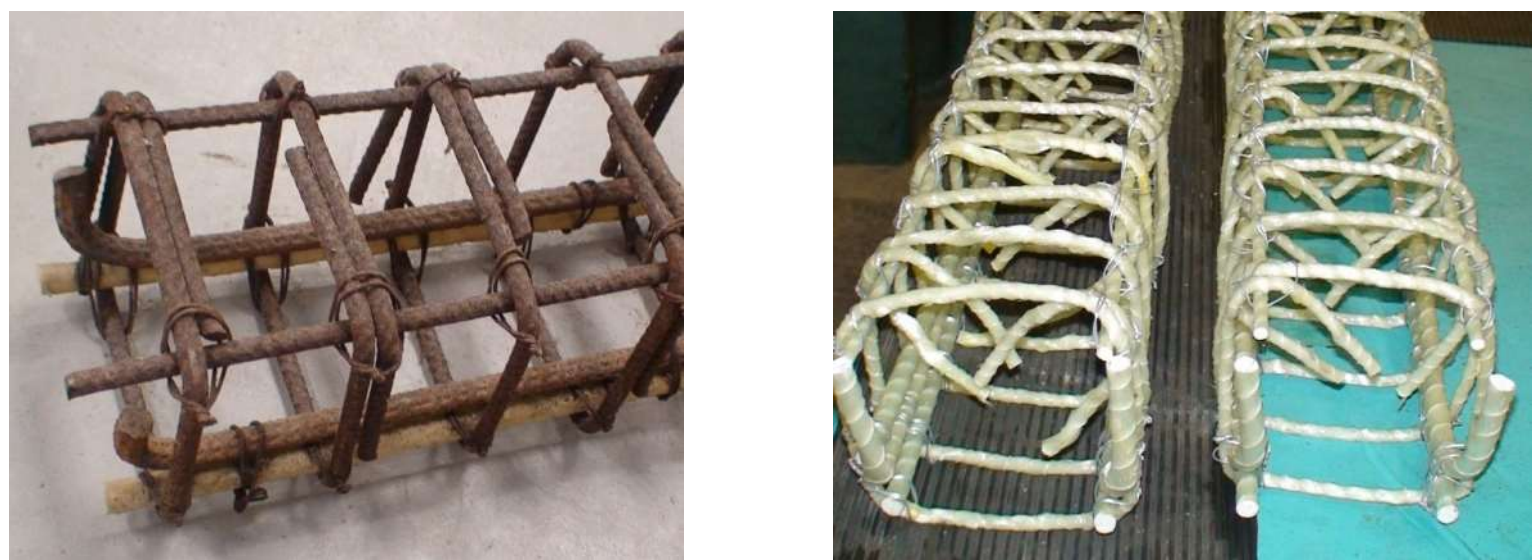

Figura 5: Gancho de aço ou GFRP nas vigas com taxa longitudinal de 0,88\%. 

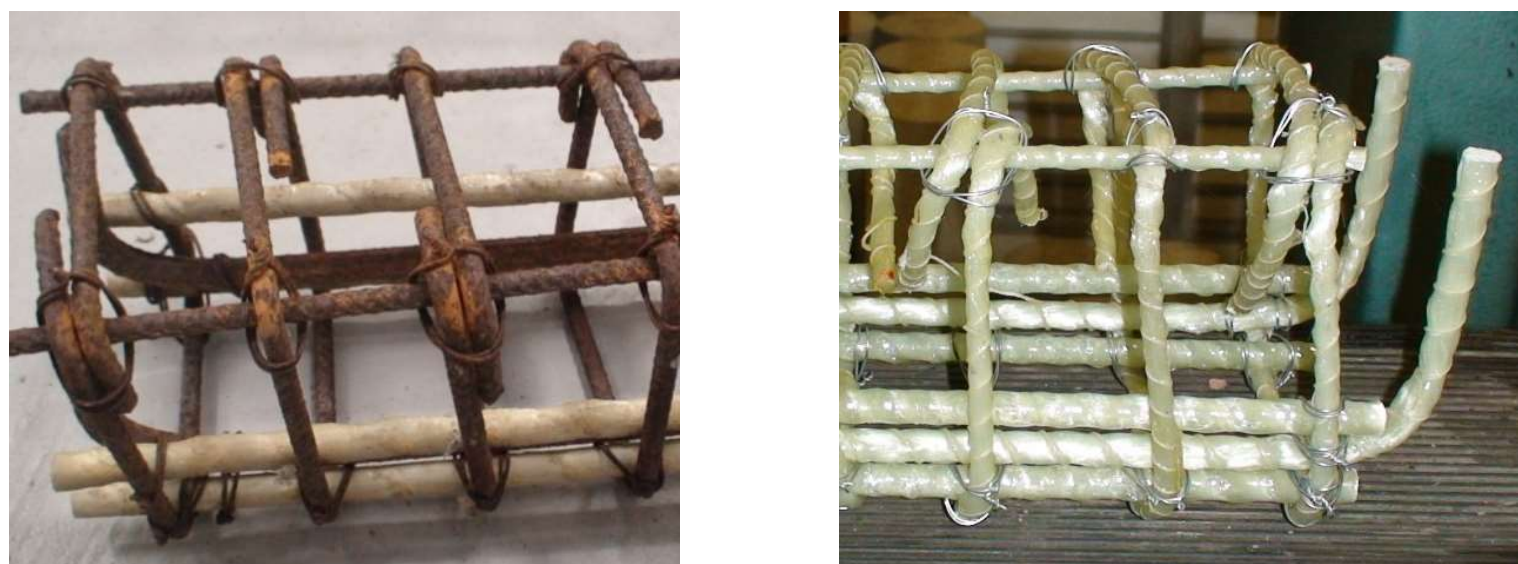

Figura 6: Gancho de aço ou GFRP nas vigas com taxa longitudinal de 2,02\%.

Tabela 1: Resultados médios dos corpos de prova de concreto por viga.

\begin{tabular}{l|l|l|l|l|l}
\hline Viga & $\mathbf{f}_{\mathbf{c}}(\mathbf{M P a})$ & $\mathbf{f}_{\mathrm{c}, \mathbf{s p}} \mathbf{( M P a )}$ & $\mathbf{E}_{\mathrm{cs}}(\mathbf{G P a})$ & $\mathbf{f}_{c, \text { sp teo }}(\mathbf{M P a})$ & \\
\hline V1-A-A-0,88 & 27,4 & 3,00 & 22,7 & 2,73 & $\mathbf{E}_{\mathrm{cs}, \text { teo }}(\mathbf{M P a})$ \\
\hline V2-A-A-2,02 & 35,8 & 3,63 & 29,2 & 3,26 & 29,5 \\
\hline V3-V-A-0,88 & 23,4 & 2,37 & 25,9 & 2,45 & 23,3 \\
\hline V4-V-A-2,02 & 24,0 & 3,10 & 30,1 & 2,50 & 23,6 \\
\hline V5-V-V-0,88 & 32,1 & 3,13 & 34,4 & 3,03 & 27,9 \\
\hline V6-V-V-2,02 & 37,3 & 3,97 & 34,1 & 3,35 & 30,6 \\
\hline
\end{tabular}

A Tabela 2 apresenta a carga $\left(P_{u}\right)$, a deformação da armadura longitudinal $\left(\varepsilon_{\mathrm{su}}\right.$ ou $\left.\varepsilon_{\mathrm{fu}}\right)$, a deformação da armadura transversal $\left(\varepsilon_{\mathrm{swu}}\right.$ ou $\left.\varepsilon_{\mathrm{fwu}}\right)$, a deformação do concreto $\left(\varepsilon_{\mathrm{cu}}\right)$, a flecha $\left(\delta_{\mathrm{u}}\right)$, a abertura máxima da fissura na flexão $\left(w_{\max }\right)$, e o espaçamento médio entre as fissuras de flexão $\left(s_{m}\right)$ na ruptura das vigas ensaiadas.

Os valores de abertura de fissura máxima $\left(w_{\max }\right)$ foram lidos na região central do vão de flexão pura na etapa de $90 \%$ da carga de ruptura, enquanto o espaçamento médio entre as fissuras de flexão é o valor médio entre os espaçamentos lidos entre as fissuras na mesma região central no nível das barras da armadura longitudinal de tração.

Tabela 2: Resultados experimentais das vigas na ruptura.

\begin{tabular}{l|l|l|l|l|l|l|l}
\hline Viga & $\mathbf{P u}_{\mathrm{u}}(\mathbf{k N})$ & $\boldsymbol{\varepsilon}_{\mathrm{su} \mathrm{ou}} \boldsymbol{\varepsilon}_{\mathrm{fu}}(\mathbf{\%})$ & $\boldsymbol{\varepsilon}_{\text {swu ou }} \boldsymbol{\varepsilon}_{\mathrm{fwu}}(\mathbf{\%})$ & $\boldsymbol{\varepsilon}_{\mathrm{cu}}(\%)$ & $\boldsymbol{\delta}_{\mathrm{u}}(\mathbf{m m})$ & $\mathbf{w}_{\max }(\mathbf{m m})$ & $\mathbf{S}_{\mathrm{m}}(\mathbf{m m})$ \\
\hline V1-A-A-0,88 & 85,9 & 16,0 & 0,3 & 2,4 & 40,8 & 0,6 & 58 \\
\hline V2-A-A-2,02 & 109,7 & 12,1 & 0,2 & 4,3 & 28,6 & 0,5 & 108 \\
\hline V3-V-A-0,88 & 43,2 & 9,1 & 0,1 & 2,5 & 38,3 & 0,6 & 132 \\
\hline V4-V-A-2,02 & 72,9 & 9,3 & 0,3 & 4,4 & 36,7 & 1,4 & 62 \\
\hline V5-V-V-0,88 & 92,1 & 19,1 & 2,5 & 5,2 & 42,2 & 2,5 & 99 \\
\hline V6-V-V-2,02 & 106,1 & 13,9 & 0,9 & 3,0 & 32,8 & 1,6 & 105 \\
\hline
\end{tabular}

Nas Figuras 7, 8, 9 e 10 podem ser vistas as curvas carga - flecha no meio do vão, carga - deformação da armadura longitudinal, carga - deformação da armadura transversal e carga - abertura de fissura das vigas ensaiadas. 

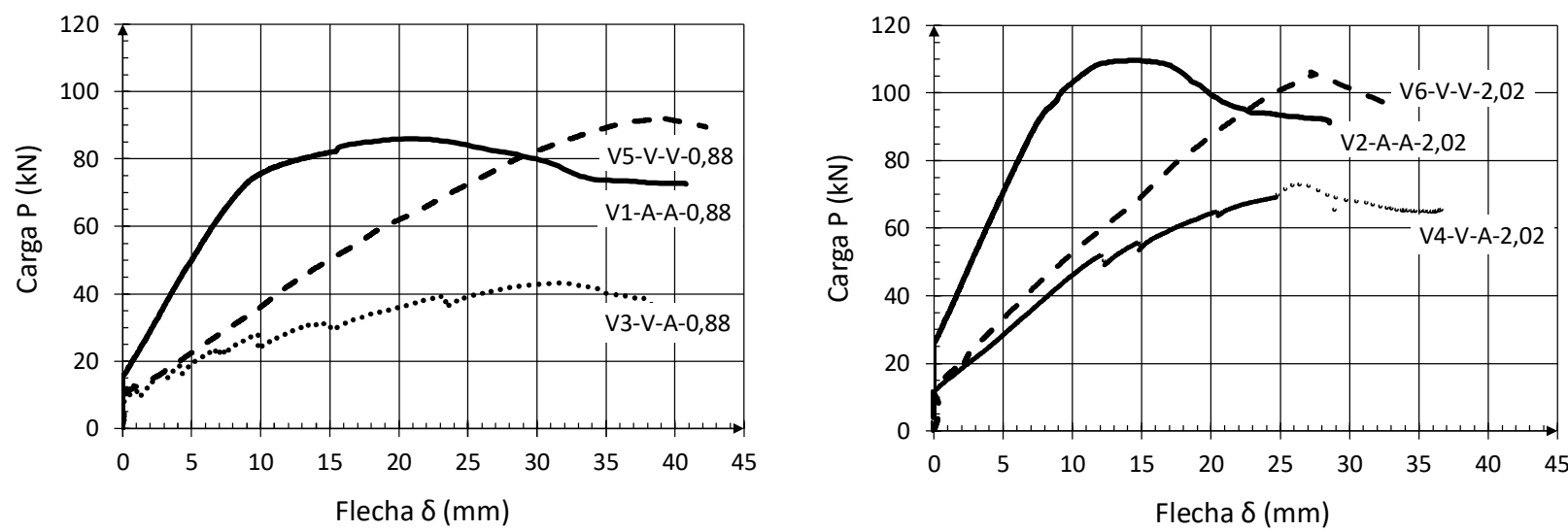

Figura 7: Curvas carga - flecha das vigas ensaiadas.
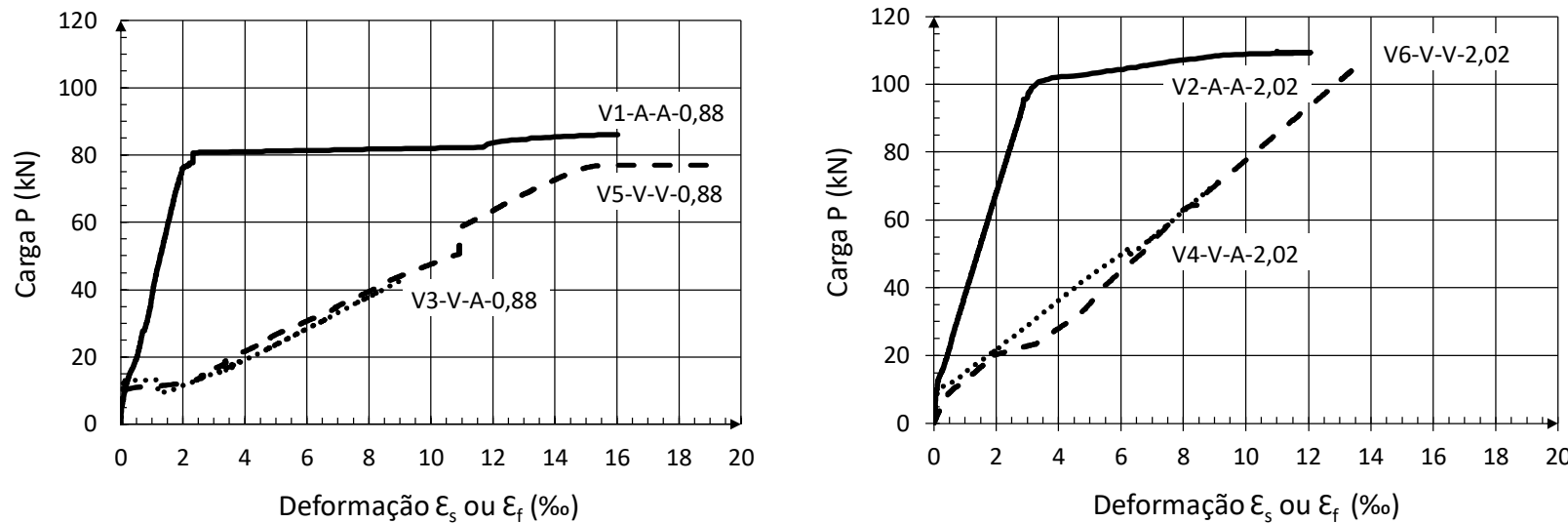

Figura 8: Curvas carga - deformação da armadura longitudinal das vigas ensaiadas.

Na Figura 11 são apresentados os padrões de fissuração na ruptura das vigas ensaiadas em sua face frontal. As vigas V1-A-A-0,88 e V2-A-A-2,02, que tinham a armadura longitudinal composta por duas e quatro barras de aço de $10 \mathrm{~mm}$ de diâmetro e estribos em aço, apresentaram modo de ruptura por flexão, com esmagamento do concreto $\left(\varepsilon_{\mathrm{cu}} \geq 2,4 \%\right.$ ) e escoamento da armadura longitudinal de aço $\left(\varepsilon_{\mathrm{su}} \geq 12,0 \%\right.$ ), cujo aspecto pós-ruptura pode ser visto nas Figuras 11a e 11b. A flecha máxima no meio do vão das vigas V1-A-A0,88 e V2-A-A-2,02 foi cerca de $41 \mathrm{~mm}$ e $29 \mathrm{~mm}$ para carga de ruptura de 85,9 kN e 109,7 kN, respectivamente.
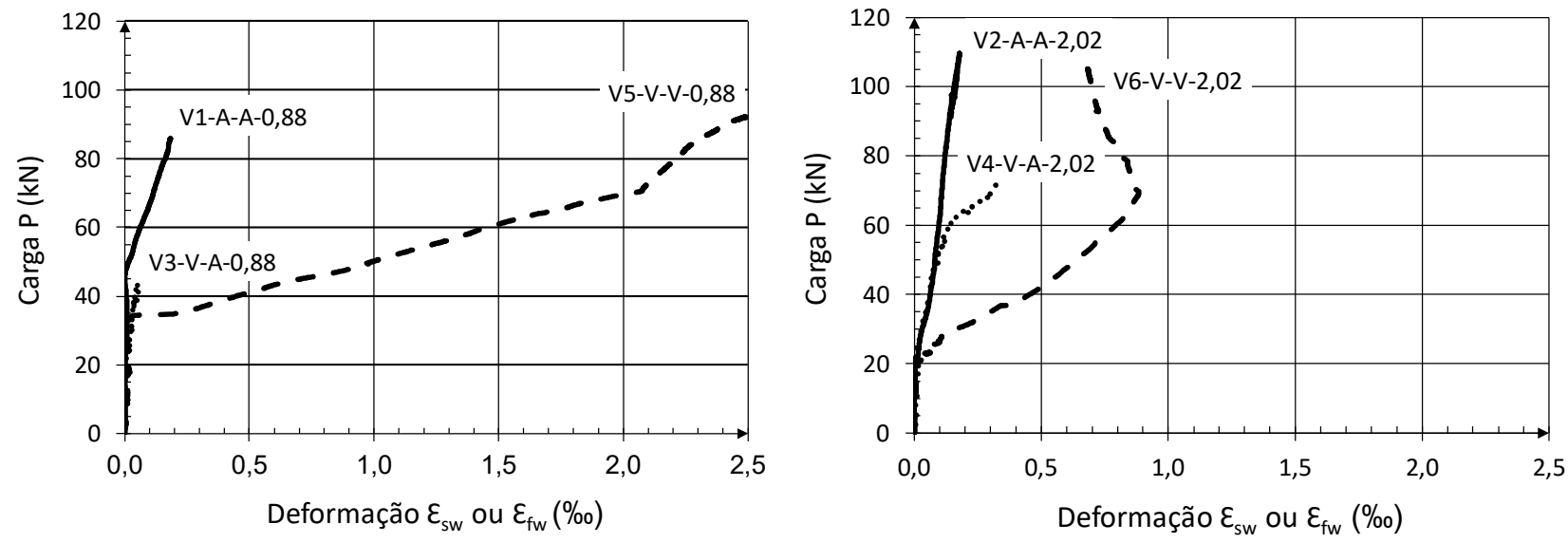

Figura 9: Curvas carga - deformação da armadura transversal das vigas ensaiadas. 

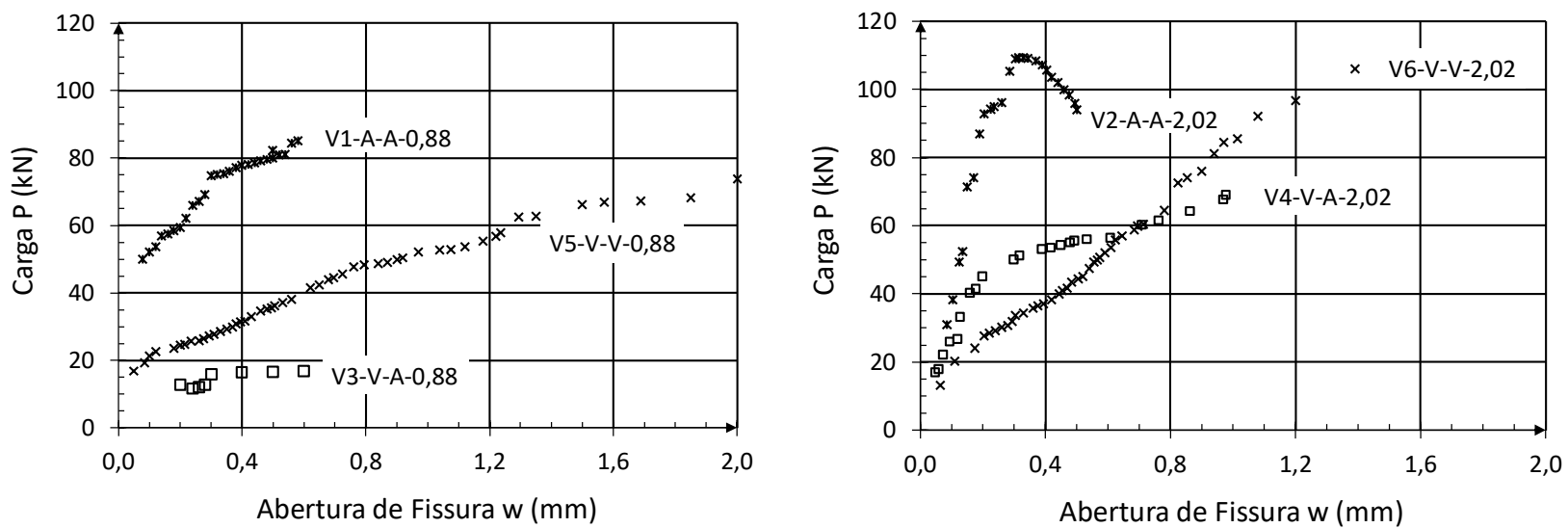

Figura 10: Curvas carga - abertura de fissura das vigas ensaiadas.

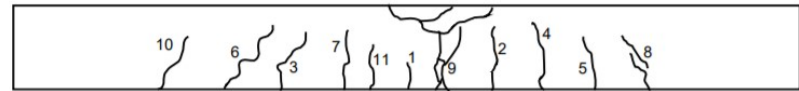

(a) V1-A-A-0,88

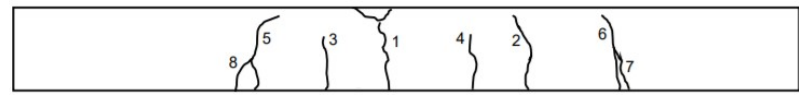

(c) V3-V-A-0,88

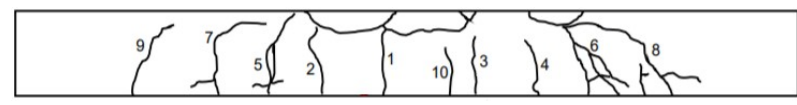

(e) V5-V-V-0,88

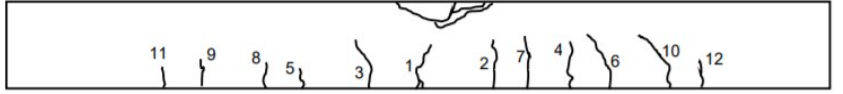

(b) V2-A-A-2,02

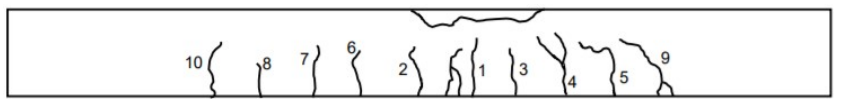

(d) V4-V-A-2,02

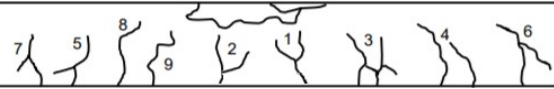

(f) V6-V-V-2,02

Figura 11: Padrão de fissuração das vigas ensaiadas.

As vigas V3-V-A-0,88 e V4-V-A-2,02, que tinham a armadura longitudinal composta por duas e quatro barras de GFRP de $10 \mathrm{~mm}$ de diâmetro e estribos de aço, também apresentaram modo de ruptura por flexão, com esmagamento do concreto $\left(\varepsilon_{\mathrm{cu}} \geq 2,5 \%\right.$ ) e ruptura da armadura longitudinal de $\operatorname{GFRP}\left(\varepsilon_{\mathrm{su}} \geq 9,1 \% \mathrm{o}\right)$, com aspecto pós-ruptura conforme Figuras 11c e 11d. Para carga de ruptura de 43,2 kN e 72,9 kN das vigas V3-VA-0,88 e V4-V-A-2,02, sua flecha máxima no meio do vão foram cerca de $38 \mathrm{~mm}$ e $37 \mathrm{~mm}$.

As vigas $\mathrm{V} 5-\mathrm{V}-\mathrm{V}-0,88$ e $\mathrm{V} 6-\mathrm{V}-\mathrm{V}-2,02$, que tinham a armadura longitudinal composta por duas e quatro barras de GFRP de $10 \mathrm{~mm}$ de diâmetro e estribos de GFRP, romperam por flexão com esmagamento do concreto $\left(\varepsilon_{\mathrm{cu}} \geq 3,0 \%\right.$ ) e armadura longitudinal de GFRP com alta deformação ( $\varepsilon_{\mathrm{su}} \geq 13,9 \%$ ), cujo aspecto pós-ruptura está mostrado nas Figuras 11e e 11f. A flecha máxima no meio do vão das viga V5-V-V-0,88 foi em torno de $41 \mathrm{~mm}$ e $29 \mathrm{~mm}$ para carga de ruptura de $85,9 \mathrm{kN}$ e 109,7 kN, respectivamente.

\section{DISCUSSÃO}

Da Tabela 1, verifica-se que os valores médios de $f_{c}$ foram em sua maioria maiores que $25 \mathrm{MPa}$, valor médio adotado para a dosagem do concreto para as vigas. Exceto para as vigas V3-V-A-0,88 e V4-V-A-2,02, o valor médio entre os valores de $f_{c}$ das vigas restantes foram em média $33 \%$ superiores a $25 \mathrm{MPa}$.

Os valores médios de $\mathrm{f}_{c, s p}$ das vigas situaram-se entre 2,37 MPa e 3,97 MPa, cuja média entre estes valores é 3,20 MPa. Fazendo-se o valor médio entre os valores de $\mathrm{f}_{c, s p}$ teo, que foram obtidos de acordo com o item 8.2.5 da norma ABNT NBR 6118 (2014), chegou-se a 2,89 MPa. Portanto, conclui-se que o valor médio 3,20 MPa é 11\% superior ao valor 2,89 MPa sugerido por norma, valor este que tende a ser conservador por segurança. 
Constata-se também da Tabela 1 que o valor médio entre os valores de $E_{\mathrm{cs}}$ foi $29,4 \mathrm{GPa}$, que é cerca

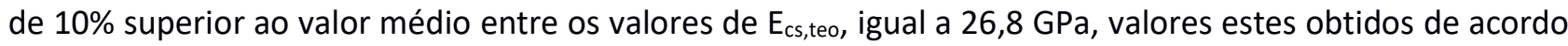
com o item 8.2.8 da norma ABNT NBR 6118 (2014).

Nota-se da Tabela 2 que as vigas com armadura longitudinal de aço (V1-A-A-0,88 e V2-A-A-2,02) e as com armaduras longitudinal de GFRP e transversal de GFRP (V5-V-V-0,88 e V6-V-V-2,02) apresentaram as maiores cargas de ruptura, enquanto as vigas com armadura longitudinal de GFRP (V3-V-A-0,88 e V4-V-A$2,02)$, as menores cargas de ruptura. Isto ocorreu devido ao fato das vigas $\mathrm{V} 5-\mathrm{V}-\mathrm{V}-0,88$ e $\mathrm{V} 6-\mathrm{V}-\mathrm{V}-2,02$ possuírem barras longitudinais de GFRP de alta resistência com elevado valor de fibras em fração volumétrica. Como esperado, quanto maior sua taxa de armadura longitudinal, maior a carga de ruptura da viga, independentemente do tipo de barra longitudinal.

Os valores de deformação última das barras longitudinais foram, em geral, maiores para as vigas com menor taxa de armadura, como mostrado na Tabela 2. Como as vigas foram superarmadas ao cisalhamento, os valores de deformação última dos estribos foram reduzidos, a não ser o da viga V5-V-V-0,88, que apresentou valor compatível com o de escoamento do aço, pois houve fissuração intensa no vão de cisalhamento, conforme se vê na Figura 11e.

Como todas as vigas ensaiadas apresentaram esmagamento do concreto na ruptura, os valores de deformação última do concreto foram superiores a 2,4\%o, tal como mostra a Tabela 2.

Em sua maioria, os maiores valores de flecha na ruptura foram atingidos pelas vigas com armadura longitudinal de GFRP, sendo os máximos para as vigas com menor taxa de armadura longitudinal interna, como pode ser notado na Tabela 2.

A Tabela 2 mostra que os maiores valores de abertura máxima da fissura na flexão ocorreram nas vigas com armadura longitudinal de GFRP, pois o coeficiente de conformação superficial e o módulo de elasticidade das barras de GFRP são menores que os das barras de aço. Além disto, a aderência entre as barras de GFRP e o concreto não é tão efetiva quanto à entre barras de aço e o concreto.

Na Tabela 3 são apresentados os valores de carga de ruptura experimentais $\left(\mathrm{P}_{\mathrm{u}, \exp }\right)$ e teóricos das vigas ensaiadas. Estes valores teóricos $\left(\mathrm{P}_{\mathrm{u}, \text { teo }}\right.$ e $\left.\mathrm{P}_{\mathrm{u} \text {,teo } \mathrm{Acl}}\right)$ foram calculados com base nas Equações 5 a 10 e no guia $\mathrm{ACl}$ 440.1R-15 (2015). Nas vigas com armadura longitudinal de GFRP, os valores $\mathrm{P}_{\mathrm{u} \text {,teo }}$ foram obtidos a partir da teoria da flexão simples admitindo-se para a deformação última das barras de GFRP valor dado pela Equação 7. Ressalta-se nesta tabela que não foram calculados os valores de carga de ruptura $P_{u, t e o ~} A C l$ das vigas com armadura longitudinal de aço (V1-A-A-0,70 e V2-A-A-1,40), pois o guia ACl 440.1R-15 (2015) trata apenas sobre vigas com armadura longitudinal de FRP.

Verifica-se que as Equações 5 a 10, sugeridas neste trabalho e baseadas na norma ABNT NBR 6118 (2014) conduziram a valores teóricos $\mathrm{P}_{\mathrm{u}, \text { teo }}$ mais próximos dos experimentais $\mathrm{P}_{\mathrm{u}, \mathrm{exp}}$, como mostra a Tabela 3 . Em média, os valores $\mathrm{P}_{\mathrm{u}, \mathrm{exp}} / \mathrm{P}_{\mathrm{u}}$ teo foram cerca de $155 \%$, para as vigas com armadura longitudinal em aço, e $128 \%$, para as vigas com armadura longitudinal em GFRP.

As formulações do guia ACl 440.1R-15 (2015), conforme Equações 1 a 4, levaram em sua maioria a valores teóricos $\mathrm{P}_{\mathrm{u}, \text { teo } \mathrm{AcI}}$ mais distantes dos experimentais $\mathrm{P}_{\mathrm{u}, \mathrm{exp}}$, de acordo com a Tabela 3. A média entre os 
valores $\mathrm{P}_{\mathrm{u}, \text { exp }} / \mathrm{P}_{\mathrm{u} \text { teo } \mathrm{ACl}}$ foi em torno dos $187 \%$. Isto pode ser explicado pelo fato do guia $\mathrm{ACl}$ 440.1R-15 (2015) recomendar valores de tensão de tração na armadura interna de FRP muito conservadores para vigas com taxa de armadura interna de FRP acima da taxa de armadura balanceada.

Tabela 3: Comparação entre cargas de ruptura experimental e teórica das vigas ensaiadas.

\begin{tabular}{|c|c|c|c|c|c|}
\hline Viga & $P_{u, \exp }$ (kN) & $P_{u, t e o}(k N)$ & $P_{u, \text { teo ACI }}(\mathbf{k N})$ & $P_{u, \exp } / P_{u, t e o}$ & $P_{u, \exp } / P_{u, \text { teo ACl }}$ \\
\hline V1-A-A-0,88 & 85,9 & 47,2 & - & 1,82 & - \\
\hline V2-A-A-2,02 & 109,7 & 86,3 & - & 1,27 & - \\
\hline V3-V-A-0,88 & 43,2 & 48,1 & 35,9 & 0,90 & 1,20 \\
\hline V4-V-A-2,02 & 72,9 & 57,1 & 37,3 & 1,28 & 1,95 \\
\hline V5-V-V-0,88 & 92,1 & 55,7 & 43,5 & 1,65 & 2,12 \\
\hline V6-V-V-2,02 & 106,1 & 83,5 & 48,5 & 1,27 & 2,19 \\
\hline
\end{tabular}

Os valores de cargas de fissuração experimental $\left(\mathrm{P}_{r, \text { exp }}\right)$ e teóricas $\left(\mathrm{P}_{\mathrm{r}, \text { teo NBR }}\right.$ e $\left.\mathrm{P}_{\mathrm{r} \text {,teo ACl }}\right)$, segundo a norma ABNT NBR 6118 (2014) e o guia ACl 440.1R-15 (2015), podem ser vistos na Tabela 4.

Tabela 4: Comparação entre cargas de fissuração experimental e teórica das vigas ensaiadas.

\begin{tabular}{l|l|l|l|l|l}
\hline Viga & $\mathbf{P}_{r, \text { exp }}(\mathbf{k N})$ & $\mathbf{P}_{r, \text { teo NBR }}(\mathbf{k N})$ & $\mathbf{P}_{r, \text { teo ACI }}(\mathbf{k N})$ & $\mathbf{P}_{\mathbf{r}, \text { exp }} / \mathbf{P}_{r, \text { teo NBR }}$ & $\mathbf{P}_{r, \text { exp }} / \mathbf{P}_{r, \text { teo ACI }}$ \\
\hline V1-A-A-0,88 & 9,7 & 7,2 & 8,1 & 0,74 & 0,84 \\
\hline V2-A-A-2,02 & 12,0 & 8,6 & 9,3 & 0,72 & 0,78 \\
\hline V3-V-A-0,88 & 9,6 & 6,4 & 7,5 & 0,67 & 0,78 \\
\hline V4-V-A-2,02 & 11,0 & 6,6 & 7.6 & 0,60 & 0,69 \\
\hline V5-V-V-0,88 & 10,8 & 8,0 & 8,8 & 0,74 & 0,81 \\
\hline V6-V-V-2,02 & 11,5 & 8,8 & 9,5 & 0,77 & 0,83 \\
\hline
\end{tabular}

Constata-se que a razão entre $P_{r, \exp }$ e $P_{r, t e o}$ foi em média 0,71 , com o uso da Equação 12 referente à norma ABNT NBR 6118 (2014), e 0,79, por meio da Equação 11 relacionada ao guia ACl 440.1R-15 (2015). 0 valor de $\alpha$, que serve para se calcular o momento de fissuração de vigas de concreto armado com barras de aço segundo a norma ABNT NBR 6118 (2014) e que depende da forma da seção transversal da viga ( $\alpha=1,5$ para vigas de seção retangular), é conservador pois leva em média a valores de $P_{r, \text { teo NBR }} 29 \%$ abaixo de $P_{r, \text { exp }}$.

Da Figura 7, nota-se que todas as curvas carga - flecha no meio do vão das vigas ensaiadas apresentaram três ramos, cada um com inclinação em relação ao eixo de carga diferente. $O$ primeiro ramo da curva refere-se à viga com concreto sem fissura. Entre o primeiro e o segundo ramos, há o início da fissuração do concreto da viga, o que leva à diminuição da inclinação da curva. Quando a viga atinge sua carga máxima, termina o segundo ramo e começa o terceiro ramo.

Todas as vigas com barras de aço, independentemente da taxa de armadura interna, apresentaram maiores inclinações que as das vigas com barras de GFRP, pois o aço é um material cujo módulo de elasticidade é cerca de 4 vezes maior que o do GFRP e influencia o comportamento da curva carga - flecha.

Em se tratando das vigas com barras de GFRP, maiores valores de rigidez à flexão foram encontrados para as vigas com barras longitudinais de GFRP e com estribos de GFRP, pois as barras de GFRP destas vigas tinham maior valor no módulo de elasticidade.

Para uma flecha no meio do vão de 5,4 mm, que é a relação obtida entre o vão da viga $(1.350 \mathrm{~mm})$ e o valor 250 e recomendada pela norma ABNT NBR 6118 (2014) para o estado limite de deformação excessiva 
com carga total, a carga resistida pelas vigas com armadura longitudinal de aço foi, em média, o dobro da carga resistida pelas vigas com armadura longitudinal de GFRP, para uma mesma taxa de armadura longitudinal.

Constatam-se na Figura 8 os comportamentos elástico-plástico das barras longitudinais de aço e linear das barras longitudinais de GFRP.

Após a fissuração do concreto, para mesma etapa de carga, a deformação das barras longitudinais de aço foi destacadamente menor que a das barras longitudinais de GFRP, pois a aderência entre o aço e concreto é maior que a entre o GFRP e o concreto. Em geral, a deformação das barras longitudinais das vigas armadas com barras longitudinais e estribos de GFRP foi similar à deformação das barras longitudinais das vigas armadas com barras longitudinais de GFRP e com estribos de aço.

Percebe-se da Figura 9 que os estribos de aço se deformaram pouco até a ruptura das vigas ensaiadas (valores menores que $0,4 \%$ ), não atingindo então a deformação de escoamento do aço. Isto ocorreu devido às vigas com estribos de aço terem sido superdimensionadas ao cisalhamento.

Destaca-se que a viga com estribo de GFRP (V5-V-V-0,88) apresentou maiores valores de deformação do estribo (valores até $2,5 \%$ ), pois surgiram fissuras inclinadas no meio do vão de cisalhamento, que podem ser visualizadas na Figura 11e.

Observa-se da Figura 10 que, para uma mesma etapa de carga, as vigas com barras de aço apresentaram menores valores de abertura de fissura de flexão. Em contrapartida, os valores de abertura de fissura de flexão para as vigas com barras de GFRP foram os maiores. Quanto maior a taxa de armadura longitudinal da viga, independentemente do tipo de barra, menor o valor de abertura de fissura de flexão.

Considerando para abertura máxima de fissura de flexão o valor igual a 0,4 mm, valor limite conforme Tabela 13.4 da norma ABNT NBR 6118 (2014) para vigas de concreto armado, a carga resistida pelas vigas com barras longitudinais de aço foi cerca de duas vezes a carga resistida pelas vigas com barras longitudinais de GFRP, para uma mesma taxa de armadura longitudinal.

A Tabela 5 agrupa os valores de carga total $\left(P_{y}\right)$ e de flecha $\left(\delta_{y}\right)$, obtidos a partir do ensaio de flexão das vigas, relativos ao valor de deformação ao escoamento da barra de aço $\left(\varepsilon_{\mathrm{sy}}=3,1 \% \mathrm{\%}\right)$, além dos valores de carga máxima $\left(\mathrm{P}_{\mathrm{u}}\right)$ e flecha para carga máxima $\left(\delta_{\mathrm{u}}\right)$.

Esses valores foram utilizados para se calcular o índice de ductilidade de flecha $\left(\mu_{\delta}\right)$, aqui definido como sendo a razão entre $\delta_{u}$ e $\delta_{y}$, que expressa o quanto a viga alcança de capacidade de se deformar inelasticamente sem perder sua resistência. Apesar das barras de GFRP não apresentarem escoamento, na Tabela 5 adotou-se que os valores de $P_{y}$ e $\delta_{y}$ para as vigas com barras de GFRP são correspondentes ao valor de deformação da barra de GFRP igual a $\varepsilon_{\text {sy }}=3,1 \%$, para fins de comparação entre os resultados de $\mu_{\delta}$.

Verifica-se da Tabela 5 que os valores de $\mu_{\delta}$ variaram de acordo com o tipo e a taxa de armadura longitudinal das vigas ensaiadas. Os valores de $\mu_{\delta}$ foram maiores para as vigas com barras de GFRP, o que expressa a maior deformabilidade destas vigas em relação às vigas com barras de aço. Entre as vigas com barras de aço, os valores de $\mu_{\delta}$ foram similares, enquanto entre as vigas com barras de GFRP, os valores de $\mu_{\delta}$ foram menores para as vigas com maior taxa de armadura longitudinal. 
Tabela 5: Valores para determinação do índice de ductilidade de flecha.

\begin{tabular}{l|l|l|l|l|l}
\hline Viga & $\mathbf{P}_{\mathbf{y}}(\mathbf{k N})$ & $\boldsymbol{\delta}_{\mathbf{y}}(\mathbf{m m})$ & $\mathbf{P u}_{\mathbf{u}}(\mathbf{k N})$ & $\boldsymbol{\delta}_{\mathbf{u}}(\mathbf{m m})$ & $\boldsymbol{\mu}_{\delta}$ \\
\hline V1-A-A-0,88 & 80,8 & 13,7 & 85,9 & 40,8 & 3,0 \\
\hline V2-A-A-2,02 & 98,1 & 8,9 & 109,7 & 28,6 & 3,2 \\
\hline V3-V-A-0,88 & 16,9 & 3,0 & 43,2 & 38,3 & 12,8 \\
\hline V4-V-A-2,02 & 29,7 & 5,5 & 72,9 & 36,7 & 6,7 \\
\hline V5-V-V-0,88 & 16,9 & 3,0 & 92,1 & 42,2 & 14,1 \\
\hline V6-V-V-2,02 & 23,1 & 2,5 & 106,1 & 32,8 & 13,1 \\
\hline
\end{tabular}

\section{CONCLUSÕES}

O presente trabalho teórico-experimental apresentou um programa experimental que contemplou o ensaio à flexão em 6 vigas de concreto armadas com barras de aço e de GFRP. De posse de todos os resultados, pôde-se obter as seguintes conclusões: - as Equações 5 a 10, sugeridas neste trabalho e baseadas na norma ABNT NBR 6118 (2014), levaram a valores teóricos de carga de ruptura mais próximos dos experimentais (cerca de 82\%) para as vigas com armadura longitudinal de GFRP, enquanto as formulações (Equações 1 a 4) do guia ACl 440.1R-15 (2015), valores teóricos mais distantes (cerca de 57\%); - a Equação 11, relacionada ao guia $\mathrm{ACl}$ 440.1R-15 (2015), conduziu a valores teóricos de carga de fissuração mais próximos dos experimentais (cerca de 78\%) para as vigas com armadura longitudinal de GFRP; - os valores de rigidez à flexão das vigas com barras longitudinais de GFRP foram menores que os das vigas com barras longitudinais de aço, pois as barras de GFRP possuem módulo de elasticidade cerca $26 \%$ do módulo de elasticidade das barras de aço; - a carga resistida pelas vigas com armadura longitudinal de aço foi, em média, o dobro da carga resistida pelas vigas com armadura longitudinal de GFRP, para uma mesma taxa de armadura longitudinal, uma flecha limite de 5,4 mm e uma abertura de fissura de flexão limite de 0,4 mm; os valores de abertura de fissura de flexão das vigas com barras de GFRP foram maiores que os das vigas com barras de aço, para uma mesma etapa de carga e quanto menor a taxa de armadura longitudinal da viga; os valores de índice de ductilidade de flecha foram maiores para as vigas com barras de GFRP com menor taxa de armadura longitudinal; - barras de GFRP de vigas de concreto podem ser utilizadas, desde que se limite sua deformação em serviço e se melhore seu coeficiente de conformação superficial a fim de diminuir sua deformabilidade e sua fissuração.

\section{REFERÊNCIAS}

ABDELKARIM, O. I.; AHMED, E. A.; MOHAMED, H. M.; BENMOKRANE, B.. Flexural strength and serviceability evaluation of concrete beams reinforced with deformed GFRP bars. Engineering Structures, v.186, p.282-296, 2019. DOI: http://doi.org/10.1016/j.engstruct.2019.02.024

ACl. American Concrete Institute. ACl 440.1R-06: Guide for the design and construction of structural concrete reinforced with FRP bars. ACI Committee 440, 2006.

$\mathrm{ACl}$. American Concrete Institute. ACl 440.1R-15: Guide for the design and construction of structural concrete reinforced with fiber-reinforced polymer bars. $\mathrm{ACl}$ Committee 440, 2015.
ABNT. Associação Brasileira de Normas Técnicas. ABNT NBR 5739. Concreto - Ensaio de compressão de corpos de prova cilíndricos. Rio de Janeiro: ABNT, 2018.

ABNT. Associação Brasileira de Normas Técnicas. ABNT NBR 6118. Projeto de estruturas de concreto - Procedimento. Rio de Janeiro: ABNT, 2014

ABNT. Associação Brasileira de Normas Técnicas. ABNT NBR 7222. Concreto e argamassa - Determinação da resistência à tração por compressão diametral de corpos de prova cilíndricos. Rio de Janeiro: ABNT, 2011.

ABNT. Associação Brasileira de Normas Técnicas. ABNT NBR 8522. Concreto - Determinação dos módulos estáticos de 
elasticidade e de deformação à compressão. Rio de Janeiro: ABNT, 2017.

ABNT. Associação Brasileira de Normas Técnicas. ABNT NBR NM 67. Concreto - Determinação da consistência pelo abatimento do tronco de cone. Rio de Janeiro: ABNT, 1998.

BENMOKRANE, B.; CHAALLAL, O.; MASMOUDI, R.. Flexural Response of Concrete Beams Reinforced with FRP Reinforcing Bars. ACl Structural Journal, v.93, n.1, p.46-55, 2008. DOI: http://doi.org/10.14359/9839

CSA. Canadian Standards Association. CAN/CSA-S806-12: Design and construction of building structures with fiberreinforced polymers. Canada: CSA Group, 2012.

CHEN, R. H. L.; CHOI, J.; GANGARAO, H. V.; KOPAC, P. A.. Steel Versus Gfrp Rebars?. Public Roads, v.72, n.2, 2008.

CHITSAZAN, I.; KOBRAEI, M.; JUMAAT, M. Z.; SHAFIGH, P.. An experimental study on the flexural behavior of FRP RC beams and a comparison of the ultimate moment capacity with $\mathrm{ACl}$. Journal of Civil Engineering and Construction Technology, v.1, n.2, p.27-42, 2010. DOI: http://doi.org/10.5897/JCECT.9000005

DIMMOCK, J.; ABRAHAMS, M.. Prediction of composite properties from fibre and matrix properties. Composites, v.1, n.2, p.87-93, 1969. DOI: http://doi.org/10.1016/0010$\underline{4361(69) 90005-6}$

HOLLAWAY, L. C.. A review of the present and future utilization of FRP composites in the civil infrastructure with reference to their important in-service properties. Construction and Building Materials, v.24, p.2419-2445, 2010. DOI:

http://doi.org/10.1016/i.conbuildmat.2010.04.062

JAY, M. L.. Bridging the gap between steel and GFRP rebar. Composites Manufacturing, v.35, n.2, p.5-6, 2019.
KARA, I. F. ASHOUR, A. F.. Flexural performance of FRP reinforced concrete beams. Composite Structures, v.94, p.1616-1625, 2012. DOI:

http://doi.org/10.1016/j.compstruct.2011.12.012

LEVY NETO, F.; PARDINI, L. C.. Compósitos estruturais: ciência e tecnologia. São Paulo: Edgar Blucher, 2006.

ORTIGÃO, J. A. R.. FRP applications in geotechnical engineering. In: ASCE MATERIALS ENGINEERING CONFERENCE, 4. Anais. Washington: Hilton Washington Hotel, 1996.

PEARCE, D. G.. Understanding CFRP as a design material. Fibre Science and Technology, v.3, n.2, p.129-146, 1970. DOI: http://doi.org/10.1016/0015-0568(70)90019-9

PENDHARI, S. S. KANT, T. DESAI, Y. M.. Application of polymer composites in civil construction: a general review. Composite Structures, v.84, p.114-124, 2008. DOI: http://doi.org/10.1016/i.compstruct.2007.06.007

SALEH, Z.; GOLDSTON, M.; REMENNIKOV, A. M.; SHEIKH, M. N.. Flexural design of GFRP bar reinforced concrete beams: An appraisal of code recommendations. Journal of Building Engineering, v.25, 2019. DOI: http://doi.org/10.1016/j.jobe.2019.100794

SILVEIRA, S. S.; FREITAS, T. C. S.; PENTEADO, J. A.; SOUZA NETO, E. A.. Metrô - RJ: Um ambiente desafiador para construções subterrâneas: o caso da estação Jardim de Alah. In: CONGRESSO BRASILEIRO DE TÚNEIS E ESTRUTURAS SUBTERRÂNEAS, 4. Anais. São Paulo: Centro de Convenções Rebouças, 2017.

TAVARES, D. H.. Análise teórica e experimental de vigas de concreto armadas com barras não metálicas de GFRP. Dissertação (Mestrado em Engenharia de Estruturas) Universidade de São Paulo, São Carlos, 2006.

A CBPC - Companhia Brasileira de Produção Científica (CNPJ: 11.221.422/0001-03) detém os direitos materiais desta publicação. Os direitos referem-se à publicação do trabalho em qualquer parte do mundo, incluindo os direitos às renovações, expansões e disseminações da contribuição, bem como outros direitos subsidiários. Todos os trabalhos publicados eletronicamente poderão posteriormente ser publicados em coletâneas impressas sob coordenação da Sustenere Publishing, da Companhia Brasileira de Produção Científica e seus parceiros autorizados. Os (as) autores (as) preservam os direitos autorais, mas não têm permissão para a publicação da contribuição em outro meio, impresso ou digital, em português ou em tradução. 